\title{
O estado de exceção, antagonismo político e "combates" à corrupção
}

DOI: 10.15175/1984-2503-202113304

\section{Victor de Oliveira Pinto Coelho*}

\begin{abstract}
Resumo
Este trabalho analisa o problema do estado de exceção, com foco na conjuntura política recente do país. Primeiro, destacamos a citação da teoria da exceção do jurista conservador Carl Schmitt em um parecer do TRF-4, que livraria o então juiz Moro de punição por ter vazado o conteúdo de uma ligação telefônica entre a presidente Dilma Rousseff e o ex-Presidente Lula. Segundo, a partir disso, buscamos apontar a relação entre o recente ativismo judicial, presente pauta da chamada "guerra à corrupção", com uma tensão de mais longa duração do Direito nas sociedades liberais, isto é, o hiato entre legalidade e legitimidade. Terceiro, finalmente, buscamos apontar que a pauta anticorrupção ganhou corpo em meio à politização e polarização do país a partir de 2013, em especial com o surgimento, em 2014, da Operação Lava Jato e o protagonismo do juiz Sérgio Moro. Nossa hipótese é a de que foi configurado, como estratégia política, um antagonismo político que dirigiu todas as demandas sociais, que emergiram em 2013, para uma oposição à "corrupção" e ao "Estado". Como marco teórico-conceitual, para a conceitualização do antagonismo político, destacamos a contribuição teórica de Ernesto Laclau e Chantal Mouffe e obras que apontam a hipertrofia da Justiça Criminal, com a centralidade da figura do inimigo. Nosso método foi a análise bibliográfica e seleção qualitativa de fontes.
\end{abstract}

Palavras-chave: Estado de exceção; legalidade; legitimidade; corrupção; antagonismo político.

\section{El estado de excepción, antagonismo político y lucha contra la corrupción}

\section{Resumen}

Este artículo analiza el problema del estado de excepción centrándose en la situación política reciente de Brasil. En primer lugar, destacamos la citación de la teoría de la excepción del jurista conservador Carl Schmitt en una sentencia del Tribunal Regional Federal 4 que liberaría al entonces juez Moro de la condena por filtrar el contenido de una llamada telefónica entre la presidenta Dilma Rousseff y el expresidente Lula. En segundo lugar, tomando la cuestión anterior como punto de partida, buscamos hacer hincapié en la relación entre el reciente activismo judicial, presente en la llamada «guerra contra la corrupción», con una tensión de derecho más duradera en el Derecho de las sociedades liberales, es decir, la brecha entre legalidad y legitimidad. . En tercer y último lugar, buscamos señalar que el criterio anticorrupción ganó cuerpo en medio de la politización y polarización del país a partir de 2013, especialmente con la aparición, en 2014, de la Operación Lava Jato

\footnotetext{
*Professor Curso de Licenciatura em Ciências Humanas do Centro de Ciências Humanas, Naturais, Saúde e Tecnologia de Pinheiro - CCHNST da Universidade Federal do Maranhão (UFMA) e do Programa de PósGraduação em História - PPGHis/UFMA onde é um dos líderes do Grupo de Pesquisa CNPq: "Poderes e Instituições, Mundos do Trabalho e Ideias Políticas - POLIMT'. Graduado e mestre em História pela Universidade Federal de Minas Gerais - UFMG; doutor em História, na linha de pesquisa Teoria e Historiografia pela Pontifícia Universidade Católica do Rio de Janeiro - PUC-Rio. Membro permanente do Programa de Pós-Graduação em História - PPGHIS/UFMA. E-mail: victor.opcoelho@ymail.com. (?ttp://lattes.cnpq.br/8493508944117492. ㄴ http://orcid.org/0000-0002-3739-7748
} 
y el protagonismo del juez Sérgio Moro. Nuestra hipótesis es que se configuró, como estrategia política, un antagonismo político que orientó todas las demandas sociales surgidas en 2013 hacia una oposición a la «corrupción» y al "Estado». Como marco teórico-conceptual, para la conceptualización del antagonismo político, destacamos la contribución teórica de Ernesto Laclau y Chantal Mouffe, y obras que señalan la hipertrofia de la justicia criminal con la centralidad de la figura del enemigo. Nuestro método fue el análisis bibliográfico y la selección cualitativa de fuentes.

Palabras clave: estado de excepción; legalidad; legitimidad; corrupción; antagonismo político.

\title{
The state of exception, political antagonism, and "wars" on corruption
}

\begin{abstract}
The following work analyzes the problem of the state of exception with a focus on Brazil's recent political situation. First, we highlight the citing of the theory of exception by conservative legal expert Carl Schmitt in the TRF-4 court, allowing the then-Judge Moro to escape punishment for having leaked the contents of a telephone call between President Dilma Rousseff and former President Lula. Second, we then use this as a basis to outline the relationship between recent legal activism, present in the so-called "war on corruption", with a longer-term tension in law in liberal societies, that is the hiatus between legality and legitimacy. Third, and finally, we seek to reveal that the anti-corruption agenda acquired impetus by means of the politicization and polarization of the country as of 2013, particularly with the emergence in 2014 of the Operação Lava Jato [Operation Car Wash] and the prominence of Judge Sérgio Moro. Our hypothesis is that a political antagonism was configured as a political strategy, framing all social demands to have emerged in 2013 as an opposition to "corruption" and the "state". As a theoretical-conceptual framework for the conceptualizing of political antagonism, we highlight the theoretical contribution of Ernesto Laclau and Chantal Mouffee and works pointing to the hypertrophy of Criminal Justice, with the central focus on of the figure of the enemy. Our method was bibliographical analysis and a qualitative selection of sources.
\end{abstract}

Keywords: State of exception; legality; legitimacy; corruption; political antagonism.

\section{État d'exception, antagonisme politique et « combats » contre la corruption}

\section{Résumé}

Ce travail analyse le problème de l'état d'exception en se basant principalement sur la conjoncture politique récente du pays. En premier lieu, nous soulignerons la mention de la théorie de l'état d'exception du juriste conservateur Carl Schmitt dans le rapport du tribunal «TRF-4 », qui a exempté de punition l'ex-juge Moro pour avoir divulgué le contenu d'un appel téléphonique entre la présidente Dilma Rousseff et l'ex-président Lula. Dans un deuxième temps, nous chercherons à montrer la relation existante entre le récent activisme judiciaire lié à ce qui a été baptisé de « guerre à la corruption » et une tension plus ancienne du droit dans les sociétés libérales, à savoir le hiatus entre légalité et légitimité. En troisième lieu, nous chercherons à montrer que l'ordre du jour anticorruption a gagné en consistance dans le cadre de la politisation et de la polarisation du pays à partir de 2013, et plus encore après la déflagration de l'Opération " Lava Jato » et la mise en avant du juge Sérgio Moro à partir de 2014. Notre hypothèse est qu'un antagonisme politique s'est configuré à partir d'une stratégie politique visant à orienter toutes les revendications sociales ayant émergé à partir de 2013 vers une opposition systématique à la « corruption » et à l' "État ». Du point de vue théorico-conceptuel, nous baserons notre conceptualisation de l'antagonisme politique sur la contribution théorique d'Ernesto Laclau et de Chantal Mouffe, ainsi que sur des ouvrages faisant état d'une hypertrophie de la justice pénale fondée sur la centralité de la figure de l'ennemi. Notre méthode a été celle de l'analyse bibliographique et de la sélection qualitative des sources.

Mots-clés : État d'exception ; légalité ; légitimité ; corruption ; antagonisme politique. 


\section{法外状态，政治对抗和巴西反腐败}

\section{摘要}

本文分析了法外状态问题，重点关注巴西最近的政治局势。首先，我们要强调的是，在巴西第四区联邦法院 (TRF-4) 庭审意见中引用了保守派法学家卡尔·施密特的例外理论，这使得当时的莫罗法官免于因泄露总统迪尔 玛.罗塞芙与前总统卢拉之间的电话内容而受到惩罚。其次，所谓 “反腐败战争” 中的司法激进主义与自由社会 中长期持续的法治之间的张力关系，即合法性与合法之间的差距。第三，反腐败议题是在 2013 年巴西政治版 图两极分化的情况下形成的，特别是随着 2014 年 “洗车行动(Lava Jato)” 和法官塞尔吉奥.莫罗在 “洗车行 动” 中的突出表现，“反腐败" 逐渐成为巴西全社会所关注的议题。在2013年，政治对抗被转化为一种政治 策略，所有社会需求都被导向对 “腐败” 的憎恨和对 “国家” 的抵抗。我们利用埃内斯托·拉克劳(Ernesto Laclau)和尚塔尔·墨菲(Chantal Mouffe)的理论，解读巴西的政治对抗模式，我们发现，当 “敌人” 的严重性 被无限放大时，刑事司法机构的权力也被迅速增大。本文的研究方法是文献分析法和资料的质性研究法。

\section{关键词：法外状态；合法；合法性；腐败；政治对抗。}

\section{Introdução: o estado de exceção no Brasil ${ }^{1}$}

Nos últimos anos, um conceito ganhou corpo nos debates e análises políticas no Brasil, o conceito de estado de exceção.

Embora não seja nosso objetivo traçar uma história do uso do conceito, é possível perceber uma ênfase do uso do conceito, no Brasil, a partir especialmente de dois casos envolvendo - ou tendo como alvo - os governos do Partido dos Trabalhadores (2003-2016). Primeiro, o caso do "Mensalão" (Ação Penal 470), um escândalo político, ainda sob governo Lula, em 2005, envolvendo denúncias de compra de votos de congressistas. Neste caso, como coloca Serrano (2016, p. 157), "alguns dos réus foram condenados pela importância política dos cargos que ocupavam no governo, e não pelas condutas em si, cuja ilicitude sequer fora devidamente comprovada no processo"; tratou-se "de um julgamento em que não foram observados valores fundamentais do processo, como presunção de inocência e devido processo legal". Segundo, temos as polêmicas em torno da chamada Operação Lava Jato que, desde 2014, passou a ter protagonismo no noticiário político. Tendo como centro a figura do juiz Sérgio Moro, da $13^{\mathrm{a}}$ Vara Criminal Federal de Curitiba, e procuradores como Deltan Dallagnol, do Ministério Público Federal de Curitiba, a operação tornou-se

\footnotetext{
1 Agradecemos à Fundação de Amparo à Pesquisa e ao Desenvolvimento Científico e Tecnológico do Maranhão - FAPEMA pelo financiamento de pesquisa da qual este artigo faz parte.
} 
protagonista no chamado "combate à corrupção", uma demanda antiga que, tornada pauta jurídica, tornar-se-ia também o norte político por excelência da oposição ao PT.

Em consonância com o que ocorrera no caso do "mensalão", houve uma guinada no sentido da condenação de réus sem que fosse tipificada a condenação por provas. No caso do "mensalão", já houvera o polêmico uso da teoria do Domínio do Fato para condenar José Dirceu, que era chefe da Casa Civil do governo PT e acusado de chefiar o esquema. Posteriormente, nas ações em torno da Lava Jato, a condenação do ex-presidente Luís Inácio Lula da Silva se deu com a admissão, por parte do juiz Moro, da a ausência de "ato de ofício" que o incriminasse diretamente. Esta condenação, mais tarde, implicaria na prisão de Lula quando este liderava pesquisas de opinião de voto para a eleição presidencial de 2018, quando o Supremo Tribunal Federal decidiu colocar em pauta a legalidade da prisão após condenação em segunda instância. Não bastassem todas essas polêmicas, em 2019 o portal The Intercept Brasil divulgou o vazamento de conversas (que haviam sido realizadas no aplicativo Telegram) entre Moro e Dallagnol e outros integrantes da Lava Jato em que se configurava interlocução indevida entre juiz e promotoria.

Nesse ínterim, houve a deposição da presidente eleita Dilma Rousseff, um impeachment sem a tipificação clara de crime de responsabilidade, o que vem justificando o uso do termo "golpe de 2016". Também nesse caso, houve um protagonismo do então juiz Sérgio Moro - que mais tarde se tornaria ministro da Justiça no governo de extremadireita de Jair Bolsonaro. Moro vazou a gravação de conversa telefônica privada entre a presidente Dilma o ex-presidente Lula, em meio às investigações em um dos processos da Lava Jato, sob o argumento de revelar ao público que Lula estaria obstruindo a justiça ao aceitar o cargo de Ministro da Casa Civil, que lhe garantiria a prerrogativa de ser julgado criminalmente $^{2}$ apenas pelo Supremo. A conversa se tornaria fato midiático e político, sendo um capítulo fundamental para a derrocada do governo.

Para o sociólogo Laymert Garcia dos Santos, em entrevista ao Jornal da Unicamp reproduzida na coletânea Historiadores pela Democracia (cf. MATTOS, BESSONE e MAMIGONIAN, 2016), nós já estaríamos num estado de exceção, dada o fato de ter sido legitimada a divulgação de um grampo da presidente da República. Citando en passant a República de Weimar (certamente em referência ao fato de que o nazismo a suplantou a

\footnotetext{
${ }^{2} \mathrm{O}$ ex-presidente Lula sofreu várias condenações, que giram em torno de acusações de recebimento pessoal de propinas, corrupção passiva e tráfico de influência envolvendo acordos com empresas de construção civil, que foram também alvos da Operação Lava Jato.
} 
partir de dentro, tendo em vista especialmente o uso do art. 48 de sua Constituição e a decretação de um estado de exceção permanente), Santos afirma que, se para as periferias nunca houve Estado de direito, vemos agora a expansão do estado de exceção em direção das disputas político-institucionais, como também coloca Serrano (2016).

Em nosso sistema repressivo e penal, que faz parte de uma política de segurança pública encarada como "guerra", temos uma presença marcante da noção de "inimigo", que justifica que a uma gama de sujeitos seja negado o direito de terem suas infrações (reais ou supostas) avaliadas e julgadas no interior do escopo das garantias legais (cf. ZAFFARONI, 2011).

A teoria da exceção e a oposição amigo-inimigo como fundamento do político são elementos importantes para um autor clássico sobre o tema da exceção: o jurista alemão Carl Schmitt (1888-1985). De forma surpreendente, a teoria da exceção schmittiana se faria presente, explicitamente, no parecer do Tribunal Regional Federal da $4^{\mathrm{a}}$ Região (TRF-4) a respeito de uma ação movida contra o juiz Sérgio Moro, devido ao caso do vazamento da ligação entre Dilma e Lula. Por 13 votos contra 1 a favor do parecer (de 22 de setembro de 2016), foi arquivado o processo, dizendo o parecer:

De início, impõe-se advertir que essas regras jurídicas (sigilo das comunicações telefônicas, Constituição, art. $5^{\circ}, \mathrm{XII}$ ) só podem ser corretamente interpretadas à luz dos fatos a que se ligam e de todo modo verificado que incidiram dentro do âmbito de normalidade por elas abrangido. É que a norma jurídica incide no plano da normalidade, não se aplicando a situações excepcionais (TRF-4, 2016, p. 4, grifo do autor).

Após uma citação de um livro do jurista brasileiro Eros Roberto Grau com menção direta a Schmitt e a Giorgio Agamben, ${ }^{3}$ segue o parecer:

Ora, é sabido que os processos e investigações criminais decorrentes da chamada "Operação Lava Jato", sob a direção do magistrado representado, constituem caso inédito (único, excepcional) no direito brasileiro. Em tais condições, neles haverá situações inéditas, que escaparão ao regramento genérico, destinado aos casos comuns. Assim, tendo o levantamento do sigilo das comunicações telefônicas de investigados na referida operação servido para preservá-la das sucessivas e notórias tentativas de obstrução, [...] é correto entender que o sigilo das

\footnotetext{
3 Autor cujas obras são referência mundial sobre o conceito de Estado de exceção mas que "não" compartilham do horizonte político conservador de Schmitt, muito pelo contrário, sem que o parecerista leve isso em consideração. Se Agamben compartilha a visão de Schmitt de que os modernos conceitos da teoria política seriam conceitos teológicos secularizados, por outro lado há uma diferença fundamental: Agamben (seguindo os passos de autores tais como Foucault e Benjamin) visa a uma "política que vem" que implica uma "deposição" do Direito e de sua lógica soberana de inclusãoexclusão; Schmitt, de seu lado, pensa a decisão soberana como restituição do Direito no âmbito de uma concepção (política e conservadora) de ordem. Daí que se vale da lógica, apontada criticamente por Agamben, do soberano que declara a exceção. Vemos que é exatamente essa lógica schmittiana que se faz presente através do parecer do TRF-4 - de forma tautológica, o parecerista acata a suspensão das normas pela afirmação de uma situação de exceção onde as normas estariam suspensas, e tal "decisão soberana” na verdade é projetada no juiz Sérgio Moro, como forma de isentá-lo.
} 
comunicações (Constituição, art. 5, XII) pode, em casos excepcionais, ser suplantado pelo interesse geral na administração da justiça e na aplicação da lei penal. A ameaça permanente à continuidade das investigações da Operação Lava Jato, inclusive mediante sugestões de alterações na legislação, constitui, sem dúvida, uma situação inédita, a merecer um tratamento excepcional” (TRF-4, 2016, p. 4-5, grifo do autor).

Se as ações da Lava Jato e a atuação do juiz Sérgio Moro foram motivo de celebração para muitos, para outros, como Bueno (2017, par. 8), por exemplo, o parecer do TRF-4 "rasurou e definitivamente maculou os princípios políticos embasadores do acordo constitucional de 1988 sem autorização nem mandato político expresso para tanto", destacando a presença de Carl Schmitt. Para Bueno (2017, par. 16), a apropriação da teoria decisionista de Schmitt representou um deslocamento da soberania popular, expressa no mandato do Executivo (referindo-se ao contexto do golpe de 2016), "para a obscuridade das ações e inspirações que movem o mundo togado, unificador do poder político para reafirmar a supremacia de seu poder".

Ou seja, por mais que pudéssemos demonstrar que a ideia do estado de exceção permanente diga respeito a uma dinâmica muito mais complexa e ampla que a de uma polarização político-partidária, é preciso reconhecer, por outro lado, que o conceito vem se tornando categoria analítica para a arena político-institucional recente. Neste presente artigo, pretendemos destacar um elemento central para uma compreensão tanto do conceito de estado de exceção - na forma paradigmática elaborada por Schmitt - como também sobre como esse conceito se mostra atual para a análise política atual: a dinâmica do "antagonismo". Se a exceção supõe a suspensão da norma tendo em vista o argumento do reestabelecimento da ordem - como observado por Agamben (2004), é essa decisão que propriamente declara o estado de exceção -, o chamado "combate à corrupção" tornase um elemento central.

\section{A exceção como espectro do ordenamento jurídico}

Em uma obra de referência sobre a reflexão a respeito do "estado de exceção", Agamben (2004) afastou sua conceitualização daquelas mais tradicionais que estabeleciam a exceção como sinônimo de "estado de sítio", "lei marcial" ou "estado de necessidade". Seu objetivo foi refletir sobre a exceção como elemento intrínseco ao direito - embora, por definição, a exceção se dê (ou se daria) numa relação de oposição à normalidade. Assim, Agamben (2004, p. 46) afirma afastar-se de uma "ingênua concepção, que pressupõe uma 
pura factualidade", para afirmar que "a necessidade, longe de apresentar-se como um dado objetivo, implica claramente um juízo subjetivo e que necessárias e excepcionais são, é evidente, apenas aquelas circunstâncias que são declaradas como tais". ${ }^{4}$ Tais reflexões ajudaram a iluminar o caráter decisionista ligado à defesa schmittiana da soberania - um poder que, guiado pela noção de ordem, não só põe o direito como pode suspender as normas como forma de (re)ativação da "Ordem".

Como coloca Serrano, diferente de qualquer discricionaridade judicial, "própria das concepções analíticas do direito", bem como da figura do "juiz solipsista que decide segundo sua consciência" ou mesmo "de qualquer caso "inequívoco de ativismo judicial ou outras formas de decisionismo" ou qualquer erro judiciário, a exceção

[...] está presente na jurisdição quando suas decisões se apresentarem como mecanismos de desconstrução do direito, com finalidade eminentemente política, seja pela suspensão da própria democracia - como ocorreu, por exemplo, na América Latina, em países como Paraguai e Honduras -, seja pela suspensão de direitos da sociedade ou parcela dela, como de fato ocorreu e ainda ocorre no Brasil em inúmeras situações (SERRANO, 2016, p. 104).

O autor destaca os casos político-jurídicos da deposição do presidente hondurenho Manuel Zelaya, em 2009, e do presidente paraguaio Fernando Lugo, em 2012, bem como, no Brasil, a jurisprudência do STF a partir do caso do "Mensalão", e chama a atenção para as características próprias da jurisdição constitucional dos países latino-americanos, incluindo o Brasil: são países "providos de Constituições analíticas (extensa), com vários dispositivos que tratam dos mais variados territórios da existência"; neles, "boa parte das decisões sobre os diversos campos da vida pública, da vida em comunidade e dos comportamentos humanos" acabam transferidas "do âmbito legislativo para o jurisdicional”, cabendo ao poder Judiciário a interpretação última e definitiva da Constituição”, ou seja, “a última palavra quanto à grande parte, se não a todas as políticas públicas e a todo o alcance significativo dos direitos fundamentais" (SERRANO, 2016, p. 105).

Estamos, aqui, no âmbito do problema do ativismo judicial, que vem ganhando destaque na arena pública brasileira nos últimos anos. Em uma entrevista dada ao portal Consultor Jurídico (ConJur) em agosto de 2014, diante da questão sobre a interferência do poder judiciário na vida do país e também tendo em conta toda a polêmica política e jurídica

\footnotetext{
${ }^{4}$ Em Homo sacer, Agamben (2002) havia colocado que, quando se deseja estabelecer um lugar próprio - uma localização territorial - para a exceção, tem-se o "campo". Seu exemplo mais contundente é a prisão de Guantánamo, mas podemos mencionar aqui, novamente, a situação das periferias e favelas das grandes cidades brasileiras.
} 
em torno da Ação Penal 470 (caso do "mensalão"), Lenio L. Streck (2017, "Leia a entrevista", par. 9) questionava:

\begin{abstract}
Porque se deu isso no Brasil? Porque temos um país em modernidade tardia, com problemas sociais enormes e aí chega em 1988 e faz uma Constituição, que coloca em seu texto promessas da modernidade. O paraíso na Constituição e o inferno na realidade. A Constituição diz que o Brasil é uma República e visa erradicar a pobreza. O que tem que se fazer então? Tem que fazer políticas públicas para isso. O Legislativo e o Executivo não fizeram, por causa do presidencialismo de coalizão. O Legislativo não foi fazendo as leis, o Executivo foi tendo que atender demandas a todo tempo, o que fez com que as pessoas corressem ao Judiciário. E o judiciário no Brasil não soube - e aí a doutrina de novo falhou - estabelecer a diferença entre judicialização e ativismo [...]. Acabamos criando o judiciário muito forte, como uma espécie de grande pai da nação. $O$ ativismo é vulgata da judicialização.
\end{abstract}

Serrano (2016) chama a atenção também para a tradição jurídica alinhada ao positivismo analítico derivado do Círculo de Viena, cuja referência máxima é Hans Kelsen e que conta também com jusfilósofos tais como Norberto Bobbio, Herbert Hart e Alf Ross. Buscando uma "pureza" metodológica que tonaria o direito autônomo com relação às esferas da moral, da política, da economia e com relação às demais disciplinas das ciências humanas - coisa fundamental, para tais autores, para haver segurança jurídica e a realização dos valores do Estado de direito, visando a diminuir ou bloquear a margem para decisões subjetivas -, a consequência é a de uma confiança na capacidade do juiz de jugar os casos concretos segundo uma racionalidade adequada ao próprio ordenamento jurídico, mesmo que decida contra a lei (SERRANO, 2016, p. 124; 134). ${ }^{5}$ É assim que, para Serrano (2016, p. 134), estamos diante de um parâmetro que confere "ao julgador um poder de imperador absolutista, totalmente incompatível com o Estado de direito que queriam defender (paradoxo da doutrina positivista)" - enfim, abre-se espaço para decisões ao estilo do soberano schmittiano.

Para o autor, autores como Kelsen ou Hart acabam deixando de fora da ciência do direito o campo da "aplicação" das normas jurídicas - que seria propício para uma redução possível de subjetivismos e da discricionariedade, com critérios racionalizáveis e que não recalquem o aspecto político, dentro de um horizonte de valores democráticos e inclusivos.

Neste ponto, no que diz respeito a esse hiato entre juízos de validação, de um lado, e demarcação dos procedimentos de aplicação, do outro, em favor dos primeiros,

\footnotetext{
${ }^{5}$ Quando Kelsen (1998) destaca, em sua Teoria pura do direito, um capítulo específico para a tarefa da interpretação, o jurista já supunha um âmbito de indeterminação referente ao momento da aplicação do direito (esfera determinante) ao caso específico - que pode decorrer inclusive da falta de clareza da lei (no âmbito da abertura do sentido verbal ou semântico) ou de duas normas que pretendem valer simultaneamente.
} 
acabamos nos lançando à tensão entre "legalidade" e "legitimidade" - distinção sobre a qual Schmitt (2007) já chamara atenção mas que foi e ainda é objeto de debate no campo da teoria jurídica de tradição liberal. Fernando Filgueiras, por exemplo, tomando como ponto de partida o caso da deposição do presidente Zelaya e o diagnóstico schmittiano, destaca o hiato entre justiça (ou legalidade) e legitimidade.

Essa zona cinzenta é produzida porque tanto o liberalismo quanto a teoria da democracia deliberativa separam os juízos de justificação ou de validação e os juízos de aplicação ou de legitimação. A distinção entre as formas de juízos, que caracteriza tanto o liberalismo quanto a teoria da democracia deliberativa, ocorre porquanto ambas as famílias de teoria política não têm uma solução para a passagem da política para a justiça, e vice-versa (FILGUEIRAS, 2012, p. 322).

No contexto atual, as polêmicas envolvendo o ativismo judicial, que não deixa de guardar relação com esse problema da relação entre legalidade e legitimidade, nos coloca diante do problema da exceção, ou seja, da suspensão das normas por apelos populistas, como bem definiu Salgado (2018), levando em consideração o "apelo à opinião pública" que vem marcando decisões judiciais no país.

Nesse sentido, a AP 470 é um marco para a visibilidade do STF: em 2009, o então ministro Joaquim Barbosa "resumiu os novos tempos, atribuindo valor a um elemento que era estranho aos ministros do STF: a aprovação das ruas", destacam Racondo e Weber (2019, p. 191), comentando uma passagem do debate em que Barbosa desafiava outro dos ministros, Gilmar Mendes, a "sair à rua". Já em 2012, outro então ministro, Ayres Brito, depois de tomar posse na presidência do tribunal e como forma de justificar ao colega Ricardo Lewandowski o fato de decidir colocar novamente em pauta a AP 470 em pleno ano eleitoral, lembrou a questão da exposição: "Havia a pressão externa como justificativa: 'O que a sociedade quer? O que a imprensa quer?', perguntou Britto, retoricamente, para logo responder: "O julgamento do mensalão. Se não julgarmos, quem será condenado seremos nós'” (RACONDO; WEBER, 2019, p. 187).

O problema, obviamente, diz respeito às consequências dessa exposição. Como se deu no caso da AP 470 e seus "julgamentos midiáticos” (CASARA, 2017, p. 100), "os limites legais e teóricos ao exercício do poder penal" foram "abandonados para permitir a punição exemplar de determinadas pessoas. Isso foi feito em franca oposição à função de garantias dos direitos fundamentais que o Supremo Tribunal Federal vinha mantendo desde a redemocratização, o que acabou", segundo o autor, "por produzir um caso exemplar de utilização explicitamente política do Sistema de Justiça Criminal” (CASARA, 2017, p. 193) 
- com destaque para a condenação de José Dirceu mediante a teoria do Domínio do Fato, condenação criticada posteriormente pelo próprio autor da teoria, o jurista alemão Claus Roxin. Para Casara (2017, p. 194, grifo nosso), em suma, com o caso do "mensalão" deuse "o 'primado do enredo sobre os fatos', que caracterizaria o processo penal do espetáculo", o que significa que "a pretensão de reconstituir por meio de provas o que de fato aconteceu acabou substituída pela necessidade de confirmar a hipótese acusatória, já afirmada pelos meios de comunicação de massa como verdadeira e previamente aceita pela maioria dos julgadores, preocupados", afirma o autor, "em dar respostas simbólicas às campanhas midiáticas contra os acusados".

Um caso também paradigmático do abuso de exposição como forma de produção de exceção é a famosa apresentação de Power Point em que Dallagnol apresentou um gráfico com várias acusações que eram direcionadas para o nome de Lula como centro de uma "organização criminosa", que teria prejudicado financeiramente a empresa estatal Petrobras. Feita em setembro de 2016 em um hotel de Curitiba, tal acusação fugia do objeto do processo em que Lula era acusado de ter recebido um triplex em Guarujá como forma de propina da empreiteira OAS, em troca de favorecimento em contratos da Petrobras. Apesar da completa ausência de critério jurídico, a apresentação ganhou destaque e foi tema de reportagens na mídia.

Enfim, embora tivessem sido comuns afirmações de que o PT pretendia "dividir o país", devido especialmente a programas sociais e políticas afirmativas (o que não deixa de ser sintomático), a "doutrina" que supõe o fundamento na divisão amigo-inimigo, como vimos, apareceria em um parecer jurídico daquele mesmo ano de 2016 que livraria o juiz Sergio Moro de punição por um ato direcionado à então presidente Rousseff e ao expresidente Lula.

Em março daquele ano, Moro afirmou que "não teve como objetivo 'gerar fato político-partidário, polêmicas ou conflitos"” (cf. ALESSI, 2016). Contudo, o "fato políticomidiático" provocado pelo vazamento foi um dos motivadores do movimento pela deposição da então presidente Dilma. Já se sabe que tal ação de uso da imprensa para exposição de alvos políticos, levada a cabo por Moro, é coerente com a análise que o mesmo fez da Operação Mãos Limpas (Itália). Em artigo de 2004, Moro observara que os "responsáveis pela operação mani pulite ainda fizeram largo uso da imprensa" (MORO, 2004, p. 59), reconhecendo que o resultado da operação foi um abalo profundo no sistema político italiano e teve como efeito colateral a eleição de Silvio Berlusconi, um magnata da mídia. 
Ainda em 2020, contudo, a figura pessoal de Moro como símbolo do "combate à corrupção" continuaria sendo sancionada por um dos ministros do Supremo, Roberto Barroso, ao comentar sobre a iminente saída de Moro do cargo de ministro da Justiça do governo de Jair Bolsonaro: "A Lava Jato e a luta contra a corrupção simbolizaram uma sociedade que deixou de aceitar o inaceitável. $E$ há pessoas que gostam mais e há pessoas que gostam menos do ministro Sérgio Moro, mas o fato é que ele é o símbolo deste processo histórico", disse Barroso, durante um debate online promovido por uma empresa de consultoria de investimentos, como destacado pelo portal de notícias UOL (cf. AMORIM, 2020).

Em sentido geral, dada a popularidade de Moro, podemos suspeitar que a natureza schmittiana do parecer do TRF-4 corresponde à legitimação da construção da figura de um potencial soberano em seu combate pela Ordem. Vejamos agora como a ideia do "combate à corrupção" nos leva do âmbito estritamente jurídico para aquele da configuração do antagonismo político.

\section{Estado de exceção como configuração do antagonismo}

Quando se fala do conceito de estado de exceção, o destaque dado a Carl Schmitt não é por acaso, pois, para além de seu posicionamento político conservador e sua inegável confluência política e teórica na época da ascensão do fascismo, o jurista alemão era um arguto analista dos dilemas do sistema político liberal. Não à toa, continua sendo um autor de referência para muitos analistas atuais, independentemente de pertencerem ao campo conservador ou ao de esquerda. No caso do parecer do TRF-4, vimos por outro lado que um dos mais problemáticos aspectos da teoria schmittiana - justamente a teoria da exceção - foi trazido diretamente para o contexto de crise política no Brasil.

Como destacou Kervégan (2006), segundo a análise consagrada pela obra de Max Weber, nos sistemas políticos contemporâneos a legalidade foi definida como parâmetro predominante da legitimidade. Para Schmitt, contudo, a legalidade é um princípio que "caracteriza o modo normal de ação e de funcionamento (forma regiminis)" do Estado e, por outro lado, "não institui uma forma de Estado (forma imperii)". Ainda que não recusasse o diagnóstico weberiano sobre uma necessária evolução (ou estruturação) burocrática condizente com a emergência do Estado legislador-parlamentar, "Schmitt julga que ela conduz necessariamente a uma crise de legitimidade que desemboca, de uma forma ou de 
outra, naquilo que chama de Estado total. Somente um princípio de legitimidade pode fundar uma política" (KERVÉGAN, 2006, p. 42).

Por "Estado total", Schmitt nomeava a configuração de um Estado administrativo que se confunde com a gênese daquilo que se afirmaria, após o fim da Segunda Guerra Mundial, como Estado de Bem-Estar Social. Ou seja, Schmitt tinha em conta o horizonte de "demandas e direitos sociais" que, segundo seu diagnóstico, traziam a conjunção de expansão administrativa do Estado, a divisão do corpo social e político, a heterogeneidade das demandas e, por fim, a própria perda de uma base segura de interpretação da lei devido à expansão desses direitos sociais. Dizendo de outra forma, há uma hipertrofia da atividade legislativa, em meio a uma disputa de interesses partidários (por sua vez representando interesses heterogêneos e crescentes), e isso levaria a uma exigência cada vez maior do poder Judiciário de se colocar em posição de intérprete.

Ou seja, em um "Estado legislador" não seria possível a neutralidade no seio do próprio poder Judiciário, colocando-se de forma dramática a questão sobre a (im)possibilidade de equilíbrio entre decisão legítima e esfera legal (cf. SÁ, 2006, p. 315), algo que a teoria jurídica contemporânea ainda busca solucionar, como vimos no item anterior.

Schmitt defendia uma via conservadora como solução, dentro da qual formulou o conceito de "Estado total qualitativo" (em oposição ao "quantitativo", meramente administrativo), que implicaria, em suma, a politização da sociedade como via para o reestabelecimento da ordem. O conceito "foi primeiramente aplicado ao fascismo italiano, cuja influência no pensamento de Schmitt é decisiva a partir do final dos anos de 1920" (KERVÉGAN, 2006, p. 72). Como coloca Kervégan (2006, p. 73), a distinção entre os dois tipos de Estado total "é menos nítida do que Schmitt deixa crer", já que ambos teriam uma estrutura burocrática e em ambos haveria uma politização da sociedade. O que interessa, na verdade, é perceber como tal distinção serve, para Schmitt, como jogo de contraposições em que a ordem liberal é colocada como o espelho negativo para a afirmação do caminho pretendido por Schmitt. "Enquanto a 'época liberal' teria pretendido proclamar o reino da objetividade e da neutralidade, Schmitt se volta pra a teologia e a metafísica como fatores estruturantes da vida política", como observa Ferreira (2004, p. 72).

Nesse sentido, se em Teologia política Schmitt (1988) afirmara que soberano é quem decide sob o estado de exceção, em O conceito do político o jurista retoma o problema da soberania para centrar foco no fundamento do próprio político: tal fundamento se baseia na polaridade amigo-inimigo, que tem caráter existencial como fundamento da unidade de um 
povo. Se a sociedade moderna é plural, seria um erro, segundo Schmitt, confundir o Estado, "unidade política paradigmática" (SCHMITT, 2015, p. 84) com qualquer outro tipo de associação, já que o Estado, numa situação limite, ainda é o guardião do jus belli. Isso não significa que o político se confunda com o Estado. Mas, a "unidade política pressupõe a possibilidade real do inimigo e, com isso, uma outra unidade política coexistente" (SCHMITT, 2015, p. 96). Embora o decisionismo não apareça de forma tão evidente nos capítulos finais desta obra, só é possível entender a crítica a esse horizonte liberal como contraparte da concepção política que se enquadra

[...] no contexto de uma tese que não pode deixar de se articular com ela, uma tese que Schmitt evoca permanentemente desde os seus primeiros textos - uma tese presente em O Valor do Estado (1914), em A Ditadura (1921), em Teologia Política (1922) e mesmo em Doutrina da Constituição (1928) - e que está subjacente à assunção, enquanto jurista, daquilo que designa como uma posição "decisionista" acerca do direito: a tese de que o Estado consiste essencialmente na realização ou efetivação (Verwirklichung) de uma ordem, ordem essa que, longe de poder ser confundida com a ordem jurídica das normas do direito, não pode deixar de lhe ser anterior, constituindo, nessa medida, a condição de possibilidade da sua vigência e aplicação (SÁ, 2015, p. 8).

Neste ponto, devemos frisar que não é possível entender tal apelo à "ordem" descolado de um contexto político - contexto que não apenas condiciona a decisão, mas sobre o qual a própria decisão incide. Como havia sido apontado por Agamben (2004), o que está em jogo aqui é uma decisão que decide, precisamente, declarar o estado de exceção. Obviamente tal decisão só será efetiva se tiver como locus alguém revestido de autoridade suficiente ou sancionada para tal. Para Schmitt, essa autoridade localizava-se paradigmaticamente na figura do chefe do Executivo. ${ }^{6}$ Mas não basta apontar a fonte de autoridade, pois é necessário ter em conta o contexto em que tal decisão - que declara o estado de exceção - busca sua legitimidade.

Voltemos, pois, a dois pontos articulados que nortearam o item anterior: a explicitação de uma medida de exceção no parecer do TRF-4 e a ideia do "combate à corrupção", ambos articulados pela Operação Lava Jato. Lembremos também que o início da operação se deu em 2014, ano de eleições presidenciais e em que aprofundava não só a explosão de politização nas ruas, ocorrida em junho de 2013, mas especialmente a

\footnotetext{
${ }^{6} \mathrm{Na}$ analogia estabelecida entre exceção e milagre, no pensamento de Schmitt “o soberano pode ser visto como o antípoda da absolutização do indivíduo no mundo liberal burguês" (FERREIRA, 2004, p. 127). A remissão do pensamento político à teologia cristã, em contraposição ao normativismo jurídico, é a defesa de que a racionalidade católica tem a "capacidade de transcender o imediato da realidade e incorporá-la em uma ordem que pressupõe algum tipo de princípio de totalização" (FERREIRA, 2004, p. 256).
} 
polarização, com o crescente antipetismo. Em meio às demandas sociais por serviços públicos - transporte, educação, saúde -, houve um crescente destaque para a pauta anticorrupção. Nas palavras de Casara (2017, p. 209), em comum ao caso do "mensalão", às ações envolvendo a Lava Jato bem como ao impeachment de Dilma Rousseff, "há a manipulação do significante 'corrupção' para afastar direitos e garantias fundamentais".

A própria exposição midiática e articulação política dos membros da Operação Lava Jato contribuíam para o destaque dessa pauta - sobre a qual, obviamente, não negamos a importância. Em junho de 2016, o procurador Deltan Dallagnol (integrante da Lava Jato) defendeu uma "mudança na cultura", uma aproximação entre Congresso e sociedade, afirmando também que a sociedade precisaria entender que é preciso derrotar a corrupção para se avançar, expressando o desejo de que "as boas pessoas venham para a política". Na ocasião, Dallagnol se fazia presente na Câmara dos Deputados para uma sessão extraordinária transformada em comissão geral para debater as chamadas "10 medidas de combate à corrupção", elaboradas e defendidas por procuradores e promotores do Ministério Público Federal em palestras e eventos em todo o país. Para o procurador, um paraíso de impunidade é um paraíso de corrupção e corrupção mata - neste caso, apelou para o significante serial killer como metáfora da corrupção: "A corrupção é uma assassina sorrateira, invisível e de massa. Ela é uma serial killer que se disfarça de buracos em estradas, em faltas de medicamentos, de crimes de rua e de pobreza” ('CORRUPÇÃO..., 2016).

Contudo, em 2013 - ano das “jornadas de junho" -, Gilberto Calil destacava que, apesar das tentativas de cooptação das manifestações pelas forças políticas e à parte os dois momentos da cobertura midiática tendenciosa, ${ }^{7}$ as manifestações, em seu início, representavam demandas populares mais variadas. Diversas pesquisas, mesmo que concentradas em São Paulo, indicavam um percentual entre $70 \%$ e $80 \%$ de trabalhadores, a maioria jovens. Embora muito plural, "a luta por direitos sociais (transporte público, saúde e educação) foi a motivação principal para a grande maioria dos manifestantes, ainda que também a 'luta contra a corrupção' fosse mencionada por parcela expressiva” (CALIL, 2013, p. 389). Já em 2015, com a consolidação do antipetismo e sua relação com pautas que pregavam a diminuição dos "gastos públicos", pesquisas de opinião com manifestantes que pediam o impeachment de Dilma Rousseff apresentaram um gap entre suas demandas por

\footnotetext{
${ }^{7}$ Primeiro, a tentativa de criminalização das manifestações e legitimação da repressão policial e, depois, a construção da narrativa antigoverno.
} 
serviços públicos, de um lado, e de outro o programa de "Estado mínimo" das lideranças liberais, como aponta Cavalcante (2018, p. 114).

Cabe recordar que tais pautas liberais estavam presentes no programa "Ponte para o Futuro", elaborado pelo partido do então vice-presidente Michel Temer, o PMDB, que prescrevia medidas tais como a desvinculação dos recursos da saúde e da educação, a desindexação dos benefícios do salário-mínimo, mudanças de idade para a aposentadoria, parecerias com setor privado, abertura comercial. Segundo do próprio Temer, um dos fundamentos do impeachment de Dilma teria sido a busca de implementação do programa (cf. VIEIRA, 2016). Em 2016, o governo Michel Temer, que sucedeu o de Dilma Rousseff, encaminhou ao Congresso a Proposta de Emenda Constitucional que determinaria a limitação dos "gastos públicos" durante 20 anos. Em 2017 foi aprovada a reforma trabalhista, que ampliava a desregulamentação das relações e contratos de trabalho.

Talvez de uma forma mais determinante para as mobilizações políticas antipetistas ocorridas no país desde 2015, há a relação simbólica entre corrupção e meritocracia. Não é nosso objetivo aqui uma discussão sobre a diferença entre mérito e a ideologia da meritocracia, mas destacar a análise feita por Sávio Cavalcante tendo como foco o contexto político recente. Cavalcante recorda que o imperativo do mérito se liga à emergência da sociedade racionalizada, tendo como foco o Estado capitalista e burocratizado que sanciona um sistema de carreiras aberto a qualquer classe social, com fundamento na impessoalidade e objetividade do processo de avaliação. E aponta que, mediante um discurso recente, para o qual são exemplos o livro autobiográfico de Dallagnol como o já citado artigo do Moro sobre a operação Mãos Limpas, a ideia do mérito é deslocada para a arena do mercado e da livre-concorrência. Nesse sentido, é estabelecida não só a oposição entre mérito e corrupção, como também entre mercado e Estado, este último como locus potencial de corrupção:

a fonte do desvirtuamento da competição não é identificada no componente propriamente burocrático, que é regido pelos princípios de recrutamento meritocrático e pela observância das normas na aplicação de suas tarefas, mas no corpo político do Estado que é regido pelo método de recrutamento imposto pelo sufrágio universal. Este aspecto permite que a classe média se torne a base social dos movimentos anticorrupção e defenda os agentes "imparciais" do poder Judiciário, ao mesmo tempo que desconfia do caráter "populista" das intenções dos agentes políticos. Não é à toa que o fenômeno mais relevante da conjuntura atual é o apoio a figuras supostamente "apolíticas", apresentadas como técnicas e dotadas de perfil gerencial. 
Assim, [...] os mecanismos e valores que valem para a competição entre indivíduos serão os mesmos aplicados à competição entre empresas no mercado (CAVALCANTE, 2018, p. 118).

Porém, o horizonte de expectativas criado em torno do "combate à corrupção" configurou-se como campo de legitimidade não para melhor aplicação do Estado democrático de direito - para retomarmos o hiato entre legalidade e legitimidade -, mas sim, como já apontado, para medidas ou declarações de exceção. $E$ isso se dava ao mesmo tempo em que o conjunto das demandas sociais, que vieram à tona em 2013, foram capturadas por um antagonismo que, paradoxalmente, fez com que tais demandas, em grande parte, fossem passadas para trás na definição das diretrizes político-econômicas oficiais. Neste ponto, cabem dois esclarecimentos.

Primeiro, com o termo "antagonismo", trazemos aqui a definição de Laclau e Mouffe (2015, p. 250, grifo dos autores): a "construção de uma identidade social - de uma posição de sujeito sobredeterminada - com base na equivalência entre um conjunto de elementos ou valores, que expelem ou externalizam os outros aos quais se opõem", dizendo respeito à "divisão do espaço social". Nesse sentido, as demandas populares adquirem força quando estabelecem uma cadeia de equivalência na mesma medida em que, através do discurso, estabelecem uma fronteira entre "nós" e "eles". Tal afirmação pode causar estranheza, pela semelhança com a argumentação schmittiana, que é foco de nossa crítica. Contudo, como deixou claro Mouffe (2000), a questão aqui é reconhecer aquele impasse entre legalidade e legitimidade que implica, assim, o reconhecimento de que o campo do político é mais extensivo que aquele da legalidade. Daí, cabe apontar, como faz a autora, tanto (i) a limitação da noção de uma racionalidade universal e prévia, que fundamenta concepções liberais sobre "razão comunicativa" como via para resolver aquele impasse, como também (ii) a limitação da própria concepção conservadora schmittiana que implica a ideia prévia e homogênea de um "povo".

Como colocou Laclau (2018, p. 230), a emergência do "povo" depende de três variáveis: (i) "relações de equivalência representadas hegemonicamente através de significantes vazios" - ou seja, que digam respeito a algo mais que uma representação direta ou significado particular, pois passam a significar um conjunto de significados e expectativas; (ii) "deslocamentos das fronteiras internas mediante a produção de significantes flutuantes" - ou seja, em momentos de crises políticas (ou crises "orgânicas"), o sistema simbólico passa por uma remodelação e tais significantes (como "povo") pode 
ser apropriado tanto à esquerda como à direita do espectro político; (iii) "e uma heterogeneidade constitutiva que torna impossíveis as recuperações dialéticas e confere à articulação política sua verdade centralidade". Assim, da mesma forma que não há um determinismo de classe na configuração dos discursos (mobilizadores de significantes), não há uma teleologia histórica que determinaria previamente o sentido das ações e configurações políticas.

Desta forma, embora no Brasil o termo "populismo" tenha sido expelido da historiografia recente por razões que não cabem discutir aqui, ele é o nome que vem sendo dado para o fenômeno recente da ascensão de políticos de extrema-direita, pretensamente "antissistema", mas cujas políticas econômicas representam o oposto do que prometem em termos de combater privilégios: representam uma agenda econômica, política e social reacionária, ainda que alimentada a partir de demandas legítimas (segurança, trabalho etc.).

Em segundo lugar, é certo que tais reflexões de Laclau e Mouffe (2015) impliquem uma rejeição de análises que apontem mistificação e engano nas ideologias políticas dado que os autores se esforçaram por se afastar de um marxismo ortodoxo que supunha a ideia de uma "verdadeira consciência" (ligada a um determinismo de classe), para, em vez disso, ressaltarem a dimensão "produtiva" dos discursos. Daí a própria substituição do termo ideologia pelos de hegemonia e discurso. Por outro lado, acreditamos que seria limitador, para a análise política, não apontar a discrepância entre o sentido proposto, base da construção de uma legitimação, e as medidas e políticas públicas adotadas.

Dessa forma, por um lado, num "momento de publicidade de casos de corrupção de um governo identificado como popular, criaram-se condições para que o combate à corrupção" [- significante flutuante - fosse] "articulado a posições de centro-direita, tornando-se equivalente a, por exemplo, Estado mínimo, mercado e liberalismo econômico", como apontou Pinto (2019, p. 23). O "combate à corrupção" trouxe, em sua dimensão discursiva, pares opositivos que incidiam diretamente sobre as disputas políticopartidárias, tornando-se um significante vazio na constituição de um discurso hegemônico pela direita - unindo diversas pautas surgidas em 2013 como emblema da luta contra "os corruptos" que teriam se aproveitado do Estado.

Assim, por outro lado, a forte divulgação midiática de casos e denúncias de corrupção teriam estimulado, como apontou também Ribeiro (2018) e Rafael Georges (cf. ANJOS, 2019), a relação entre governos petistas e corrupção. A própria Lava Jato não contribuiu apenas na escolha preferencial dos alvos - em princípio, uma escolha legítima 
já que visou antes ao partido que estava, então, ocupando o poder em nível federal -, mas também pelo próprio posicionamento antipetista por parte de alguns de seus delegados, como ocorreu durante a disputa eleitoral para presidência da república, em 2014. Além de demonstrarem preferência pelo candidato Aécio Neves, do PSDB, que disputava o segundo turno da eleição com Dilma Rousseff, do PT, mais as críticas ao ex-presidente Lula, havia também um grupo do Facebook, do qual participava um dos delegados ligados à Lava Jato,

chamado Organização de Combate à Corrupção, cujo símbolo é uma caricatura de Dilma, com dois grandes dentes incisivos para fora da boca e coberta por uma faixa vermelha na qual está escrito "Fora, PT!". Esse grupo se autoproclama um instituto cujo objetivo é mostrar às pessoas que "o comunismo e o socialismo são um grande mal que ameaça a sociedade” (DUAILIBI, 2014).

Somada à construção da equivalência entre corrupção, petismo e esquerdismo, houve enfim a associação entre corrupção e "tamanho do Estado". A política econômica vitoriosa em termos da conquista do poder, construída a partir da plataforma antipetista, trouxe a PEC dos 20 anos, a reforma trabalhista (cujos efeitos foi a substituição de direitos trabalhistas por mais precarização, além de não ter gerado a gama de criação de empregos como prometia) e toda uma agenda que visa à chamada "desoneração do capital".

Assim, não por acaso estudiosos do próprio campo jurídico vêm se dedicando a analisar a relação entre políticas econômicas neoliberais (ou de "austeridade") e a invasão do direito penal do inimigo na esfera da jurisdição - como mostra duas obras lançadas em 2017, a de Rubens Casara, já mencionada, e a de Rafael Valim (2017). Num país como o Brasil, estruturalmente constituído para a gestão dos excluídos, o cenário se agrava com a expansão da ideia do inimigo interno, agora "plasmado na figura do corrupto, a quem são negadas as mais óbvias garantias processuais enfeixadas no princípio do devido processo legal, em uma guerra que desconhece limites. Nesse sentido”, coloca Valim (2017, cap. 3, posição 449), "o enfrentamento da corrupção, enquanto desafio fundamental das democracias contemporâneas, passa a constituir um cavalo de troia dentro do Estado de Direito, sendo usado em favor de interesses inconfessáveis".

\section{Considerações finais}

O diagnóstico de Schmitt sobre os dilemas da sociedade liberal e pluralista continuam atuais - tão atuais que, como vimos, trazem o risco da atualização de suas soluções conservadoras e reacionárias. Antes de tudo, os dilemas que recaem sobre o Poder 
Judiciário, no hiato entre legalidade e legitimidade, parecem sempre colocar em cena os limites entre judicialização política e ativismo judiciário. Nesse sentido, as ambições e leituras que desejavam isolar a esfera jurídica do campo das disputas políticas não passam de uma ilusão, embora constatar isso não deva ser confundido com a relativização da legalidade diante da ideia do "apelo popular" - algo que Salgado (2018) definiu como "gramática populista”. Quando o imperativo deve ser o respeito e consolidação dos preceitos democráticos, inscritos numa Constituição ainda recente, tal populismo jurídico corre o risco de passar por cima do componente contramajoritário que deve nortear a atuação dos magistrados, sem falar na suspensão arbitrária - ou "schmittiana" - das normas.

$\mathrm{Na}$ conjuntura atual, a exposição do Judiciário vem tendo o efeito de virar contra si mesmo seu ativismo devido às repercussões políticas, especialmente após a politização e polarização verificadas no país a partir de 2013. Além das polêmicas surgidas em torno de pautas no âmbito de direitos civis (como a recente criminalização da homofobia), já há análises dentro do próprio meio jurídico que, além de apontarem a hipertrofia da Justiça Criminal (CASARA, 2017), também criticam um alinhamento do Judiciário com a pauta neoliberal de desmantelamento de direitos sociais e destituição da Justiça do Trabalho (PAIXÃO; LOURENÇO FILHO, 2020). No antagonismo político em que o Judiciário se fez presente como ator, pautas conservadoras foram unificadas sobre o significante "combate à corrupção".

Enfim, como procuramos apontar, o Judiciário também não está imune ao ambiente político e por isso é se faz cada vez mais urgente uma compreensão dos conceitos e do que está em jogo quando se fala sobre ativismo judicial, populismo jurídico e, sobretudo, estado de exceção.

\section{Referências}

AGAMBEN, Giorgio. Homo sacer: o poder soberano e a vida nua. Tradução de Henrique Burigo. Belo Horizonte: UFMG, 2002.

AGAMBEN, Giorgio. Estado de exceção. Tradução de Iraci D. Poleti. São Paulo: Boitempo, 2004.

ALESSI, Gil. Sérgio Moro pede desculpa por "polêmica" de áudios de Lula e isenta Dilma. El País Brasil, 31 mar 2016. Disponível em: https://brasil.elpais.com/brasil/2016/03/30/politica/1459296826_155962.html. Acesso em: 30 mar. 2019. 
AMORIM, Felipe. Saída de Moro revela 'arrefecimento' no combate à corrupção, diz Barros. UOL - Política, 24 abr. 2020. Disponível em: https://noticias.uol.com.br/politica/ultimasnoticias/2020/04/24/saida-de-moro-e-arrefecimento-no-combate-a-corrupcao-diz-barroso-dostf.htm?cmpid=copiaecola. Acesso em: 22 jun. 2020.

ANJOS, Anna Beatriz. Brasileiros não querem "Estado mínimo", diz cientista político (entrevista com Rafael Georges). Agência Pública, 10 abr. 2019. Disponível em: https://apublica.org/2019/04/brasileiros-nao-querem-estado-minimo-diz-cientista-

politico/?fbclid=IwAR3W0d_Nb4NFywr-1qOumA3f22-

rhdeydRoeqYM7RyidKnLaĒ1DWj5o6Mow. Acesso em: 27 mar. 2019.

BUENO, Roberto. Carl Schmitt no TRF-4: o estado de exceção no Brasil. Brasil 247, 13 dez. 2017. Disponível em: https://www.brasil247.com/blog/carl-schmitt-no-trf-4-o-estadode-excecao-no-brasil. Acesso em: 20 maio 2020.

CALIL, Gilberto. Embates e disputas em torno das jornadas de junho. Projeto História, São Paulo, n. 47, p. 377-403, ago. 2013. Disponível em: https://revistas.pucsp.br/index.php/revph/article/viewFile/17155/14571. Acesso em: 15 jan. 2020.

CASARA, Rubens. Estado pós-democrático: neo-obscurantismo e gestão dos indesejáveis. Rio de Janeiro: Civilização Brasileira, 2017.

CAVALCANTE, Sávio. Classe média, meritocracia e corrupção. Crítica Marxista, n. 46, p. 103-125, 2018.

Disponível

em: https://www.ifch.unicamp.br/criticamarxista/arquivos_biblioteca/artigo2018_06_29_21_18_52. pdf. Acesso em: 19 set. 2019.

'CORRUPÇÃO mata', diz procurador da Lava Jato no plenário da Câmara. G1 - Política, 22 jun. 2016. Disponível em: http://glo.bo/28Pbzb1. Acesso em: 15 de jun. 2020.

DUAILIBI, Julia. Delegados da Lava Jato exaltam Aécio e atacam PT na rede. O Estado de São Paulo, 13 nov. 2014. Disponível [apenas para assinantes] em: https://politica.estadao.com.br/noticias/geral,delegados-da-lava-jato-exaltam-aecio-e-atacampt-na-rede,1591953. Acesso em: 3 abr. 2019.

FERREIRA, Bernardo. O risco do político: crítica ao liberalismo e teoria política no pensamento de Carl Schmitt. Rio de Janeiro: IUPERJ, 2004.

FILGUEIRAS, Fernando. Justiça constitucional, legitimidade e interesse público. Revista Brasileira de Ciência Política, n. 7, p. 319-347, abr. 2012. Disponível em: https://www.scielo.br/j/rbcpol/a/7GthZCxdPT8H8C5pm6sBtxz/?lang=pt. Acesso em: 12 mar. 2019.

KELSEN, Hans. Teoria pura do direito. Tradução de João Baptista Machado. 6. ed. São Saulo: Martins Fontes, 1998.

KERVÉGAN, Jean-François. Hegel, Carl Schmitt: o político entre a especulação e a positividade. Tradução de Carolina Huang. Barueri: Manole, 2006. 
LACLAU, Ernesto. A razão populista. Tradução de Marcos Eugênio Marcondes de Moura. São Paulo: Três Estrelas, 2018.

LACLAU, Ernesto; MOUFFE, Chantal. Hegemonia e estratégia socialista: por uma política democrática radical. Tradução de Joanildo A. Burity, Josias de Paula Jr. e Aécio Amaral. São Paulo: Intermeios, 2015.

MATTOS, Hebe; BESSONE, Tânia; MAMIGONIAN, Beatriz G. Historiadores pela democracia: o golpe de 2016 e a força do passado. São Paulo: Alameda, 2016. (e-book Kindle).

MORO, Sérgio F. Considerações sobre a operação mani pulite. Revista do Centro de Estudos Jurídicos, Brasília, n. 26, p. 56-62, jul./set. 2004. Disponível em: http://www.jf.jus.br/ojs2/index.php/revcej/article/view/625/805. Acesso em: 19 maio 2018.

MOUFFE, Chantal. Schmitt and the paradox of liberal democracy. In: The democratic paradox. London, New York: Verso, 2000. p. 36-59.

PAIXÃO, Cristiano; LOURENÇO FILHO, Ricardo. O STF e o Direito do Trabalho: as três fases da destruição. UnB Notícias, 31 jul. 2020. Disponível em: https://noticias.unb.br/artigos-main/4332-o-stf-e-o-direito-do-trabalho-as-tres-fases-dadestruicao. Acesso em: 15 de jun. 2020.

PINTO, Céli Regina Jardim. A trajetória discursiva das manifestações de rua no Brasil (2013-2015). In: SOLANO, Esther; ROCHA, Camila (Org.). As direitas nas redes e nas ruas: a crise política no Brasil. São Paulo: Expressão Popular, 2019, p. 15-53.

RACONDO, Felipe; WEBER, Luiz. Os onze: O STF, seus bastidores e suas crises. São Paulo: Companhia das Letras, 2019.

RIBEIRO, Márcio Moretto. Antipetismo e conservadorismo no Facebook. In: SOLANO, Esther (Org.). O ódio como política: a reinvenção da direita no Brasil. São Paulo: Boitempo, 2018. p. 85-90.

SÁ, Alexandre Guilherme Barroso de Matos Franco de. O poder pelo poder: ficção e ordem no combate de Carl Schmitt em torno do poder. 2006. Dissertação (Doutorado em Filosofia Moderna e Contemporânea)-Faculdade de Letras, Universidade de Coimbra, Coimbra, 2006. Disponível em: http://hdl.handle.net/10316/610. Acesso em: 20 jun. 2020.

SÁ, Alexandre Guilherme Barroso de Matos Franco de. Introdução: "O conceito do político" de Carl Schmitt. In: SCHMITT, Carl. O conceito do político. Tradução, introdução e notas de Alexandre Franco de Sá. Lisboa: Edições 70, 2015. p. 7-23.

SALGADO, Eneida Desiree. Populismo judicial, moralismo e o desprezo à Constituição: a democracia entre velhos e novos inimigos. Revista Brasileira de Estudos Políticos, Belo Horizonte, v. 117, p. 193-217, jul./dez. 2018. Disponível em: https://pos.direito.ufmg.br/rbep/index.php/rbep/article/view/594. Acesso em: 8 dez. 2018.

SCHMITT, Carl. Théologie Politique: (1922, 1969). Tradução de Jean-Louis Schlegel. Paris: Gallimard, 1988. 
SCHMITT, Carl. Legalidade e legitimidade. Tradução de Tito Lívio Cruz Romão. Belo Horizonte: Del Rey, 2007.

SCHMITT, Carl. O conceito do político. Tradução, introdução e notas de Alexandre Franco de Sá. Lisboa: Edições 70, 2015.

SERRANO, Pedro Estevam A. P. Autoritarismo e golpes na América Latina: breve ensaio sobre jurisdição e exceção. São Paulo: Alameda, 2016.

STRECK, Lenio L. Abandonar as próprias vontades para julgar é o custo da democracia. ConJur, 8 ago. 2017 (entrevista originalmente publicada em 10 ago. 2014). Disponível em: https://www.conjur.com.br/20anos/2017-ago-08/lenio-streck-abandonar-as-proprias-vontadespara-julgar-e-o-custo. Acesso em: 8 abr. 2019.

TRIBUNAL REGIONAL FEDERAL DA $4^{\mathrm{a}}$ REGIÃO. P.A. Corte Especial $n^{\circ} 0003021$ 32.2016.4.04.8000/RS. Relator: Des. Federal Rômulo Pizzolatti, 2016, p. 1-5. Disponível em: https://s.conjur.com.br/dl/lava-jato-nao-seguir-regras-casos.pdf. Acesso em: 10 abr. 2018.

VALIM, Rafael. Estado de exceção: a forma jurídica do neoliberalismo. São Paulo: Contracorrente, 2017. (e-book Kindle).

VIEIRA, Inacio. Michel Temer diz que impeachment aconteceu porque Dilma rejeitou "Ponte para o Futuro". The Intercept-Brasil, 22 set. 2016. Disponível em: https://theintercept.com/2016/09/22/michel-temer-diz-que-impeachment-aconteceu-porquedilma-rejeitou-ponte-para-o-futuro/. Acesso em: 27 set. 2019.

ZAFFARONI, Eugenio Raúl. O inimigo no direito penal. Tradução de Sérgio Lamarão. 3. ed. Rio de Janeiro: Revan, 2011. 